\title{
A EDUCAÇÃO NO SISTEMA PRISIONAL: EXPERIÊNCIA EDUCACIONAL NA PENITENCIÁRIA ESTADUAL DE FRANCISCO BELTRÃO/PR
}

\author{
EDUCATION IN THE PRISON SYSTEM: EDUCATIONAL EXPERIENCE IN FRANCISCO BELTRÃO STATE PENITENTIARY/PR
}

EDUCACIÓN EN EL SISTEMA CARCELARIO: EXPERIENCIA EDUCATIVA EN FRANCISCO BELTRÃO PENITENCIARÍA ESTATAL / PR

\author{
MENEGOTO, Camila Taís ${ }^{1}$ \\ WENCZENOVICZ, Thaís Janaina ${ }^{2}$
}

\section{RESUMO}

A educação prisional é tratada como programa eventual de governo ao invés de uma política pública de Estado. Costumeiramente a falta estrutura física, material pedagógico adequado e professores comprometem a efetividade desse direito. O estudo aborda o acesso à educação pelos apenados no Estado do Paraná por meio de pesquisa de campo realizada na Penitenciária Estadual de Francisco Beltrão/PR. A educação é dever do Estado, tratando-se de um direito universal e, aos apenados assenta-se na Lei de Execução Penal ( $n^{\circ}$ 7.210/1984). Enquanto procedimento metodológico utiliza-se o estudo de caso e a história oral temática, a fim de evidenciar fatos concretos do sistema prisional brasileiro.

Palavras-chave: Educação de apenados. Paraná. Sistema Prisional.

\section{ABSTRACT}

Prison education is treated as a temporary government program rather than a state public policy. Usually what compromise the effectiveness of this right is the lack of physical structure, the lack of adequate pedagogical material and the lack of teachers. The study approaches the access to education for the inmates in the State of Parana through field research carried out in the Francisco Beltrão State Prison/ PR. Education is a state duty, an universal right, and for inmates this right is based on the Law of Criminal Execution ( $\left.N^{\circ} 7.210 / 1984\right)$. As a methodological procedure we use the case study and storytelling technique in order to highlight concrete facts of the Brazilian prison system.

Keywords: Education of the inmates. Paraná. Prison system.

\section{RESUMEN}

La educación penitenciaria es tratada como un programa eventual gubernamental en lugar de una política pública estatal. Por lo general, la falta de estructura física, de material pedagógico adecuado y de maestros es lo que compromete la efectividad de este derecho. El estudio aborda el acceso a la educación de las personas privadas de libertad (PPL) en el Estado de Paraná a través de una investigación de campo realizada en la prisión estatal/PR Francisco Beltrão. La educación es un deber del estado, ya que es un derecho universal y para los PPL este derecho está basado en la Ley de Ejecución Penal ( $N^{\circ}$ 7.210/1984). Como procedimiento metodológico, utilizamos el estudio de caso y la historia hablada para destacar hechos concretos del sistema penitenciario brasileño.

Palabras clave: Educación de los internos. Paraná. Sistema penitenciario.

\footnotetext{
${ }^{1}$ Universidade Estadual do Oeste do Paraná - UNIOESTE - Brasil.

2 Universidade Estadual do Rio Grande do Sul - UERGS - Brasil; Universidade Estadual do Paraná - UNIOESTE Brasil.
} 


\section{INTRODUÇÃO}

O aumento da taxa de criminalidade nos últimos anos tem levado a insegurança social nos grandes e médios centros urbanos. Na última década, também se percebeu a propagação da violência em razão da ampla divulgação por meio das comunicações/mídias (jornais, televisão, aplicativos, etc.) e vivenciada por uma parcela significativa da sociedade. Pode-se verificar o impacto dessa situação quando medidas extremas são tomadas, como exemplo, com aplicação pela primeira vez do artigo 34 da Constituição Federal/1988, que ordenou o Estado do Rio de Janeiro a Intervenção Federal em $2018^{3}$.

O controle social se utiliza do sistema penal, e as medidas institucionais são tentativas de minimizar as crescentes taxas de criminalidade violenta e organizada. Observa-se que há perda das eficácias da segurança pública quanto ao controle social. É nesse contexto, que se aplica em parte a educação como direito universal. Trata-se também de um Direito Humano e Fundamental em acordo a normatização jurídica brasileira, principalmente na Constituição Federal.

Neste trabalho, analisar-se-á o ensino escolar como direito do cidadão condenado a pena privativa de liberdade no sistema penitenciário. Para o aprimoramento do trabalho é necessário verificar na prática como ocorre o acesso à educação no sistema prisional. Além da bibliografia investigada, a pesquisa é baseada no estudo de caso referente à assistência educacional no sistema prisional.

A pesquisa de campo foi realizada na Penitenciária Estadual de Francisco Beltrão - PR, localizada no Sudoeste do Estado do Paraná - unidade prisional masculina e de segurança média. A escolha do local se deu em razão do acesso das pesquisadoras aos acervos documentais e visitas in loco pelo fato de ser essa uma penitenciária construída recentemente, a qual sugestiona-se enquanto política pública adoção de ações e práticas administrativas e de gestão atualizadas aos debates atuais sobre a vida no cárcere. Ocorreu a aplicação de 175 questionários para os apenados que auferem da assistência educacional na respectiva unidade. As perguntas se referiram aos aspectos sociais dos apenados e com ênfase aos processos educacionais.

O acesso ao ensino escolar pelos apenados dá-se por meio da assistência educacional, assegurada pela Lei de Execução Penal que compreende a instrução escolar e a formação profissional do preso e do internado, com ensino de primeiro grau (Ensino Fundamental), de forma obrigatória, com Ensino Médio, regular ou supletivo (Educação para Jovens e Adultos), com formação geral ou educação profissional de nível médio, atendendo a universalização do ensino como direito de todos.

Em relação ao Estado do Paraná, a escolarização desenvolvida nas prisões ocorre por intermédio dos Centros Estaduais de Educação Básica para Jovens e Adultos/CEEBJAs, que dentro das unidades prisionais foram inseridos exclusivamente para atender os apenados.

Para analisar a implementação de ações afirmativas ao acesso à assistência educacional no estabelecimento prisional, no Município de Francisco Beltrão - PR, o método identificado como o

\footnotetext{
${ }^{3}$ A decisão foi instituída por meio do Decreto n.o 9.288, de 16 de fevereiro de 2018, outorgado pelo Presidente da República. Como interventor, foi nomeado o general de Exército Walter Souza Braga Netto, comandante do Comando Militar do Leste, localizado na cidade do Rio de Janeiro.
} 
adequado é o estudo de caso. Utilizou-se também do uso da metodologia de História Oral Temática4, nesse caso por meio de entrevista com o ex-apenado cursando o Ensino Superior, conforme critério de experiência com a assistência educacional.

\section{SISTEMA PENITENCIÁRIO DO ESTADO DO PARANÁ: A IMPORTÂNCIA DA ASSISTÊNCIA EDUCACIONAL}

A criação de instituições prisionais, das leis e teorias criminais teve seu início a partir do século XVII, na sociedade moderna. Já o encarceramento de pessoas que transgridem as regras sociais, surgiu antes da história ocidental cristã (Escola de Formação e Aperfeiçoamento Penitenciário ESPEN). Para Silveira (2009, p. 16), a efetivação do sistema prisional no Paraná ocorreu a partir da Primeira República, com atividades educacionais e laborativas dentro dos presídios, baseado nas técnicas europeias e americanas.

Para o DEPEN/PR em 02 de junho de 1880 se estabeleceram objetivos para a construção da primeira penitenciária da Província, que contou com a presença do Presidente da Província Manoel de Souza Dantas Filho, Imperador D. Pedro II, e do Chefe da Polícia. Nesse período, por motivos financeiros e políticos, com a queda do Império, a construção da penitenciária foi adiada. Somente em 1905, o governo adquire um edifício, no bairro denominado Ahú, em Curitiba.

Por meio da Lei $n^{\circ}$ 808, de 05 de maio de 1908, se autorizou ao Poder Executivo instituir o regime penitenciário no Estado, momento a qual ocorreu à instalação da penitenciária. A unidade foi denominada de Prisão Provisória do Ahú. Finalmente instalada em 1909, a unidade contava com 52 celas individuais, 49 para homens e 6 para mulheres. De início, foi adotado o sistema penitenciário americano Auburn (silent system), de rígida disciplina, em que o preso era confinado na cela para expiação da sua culpa, por meio do trabalho e em isolamento absoluto.

A penitenciária foi desativada em 2006, e os encarcerados transferidos para estabelecimentos penais na região metropolitana de Curitiba. O prédio foi destinado à instalação do Fórum Criminal e dos Juízos Especiais do Centro Judiciário de Curitiba. O sistema penitenciário do Paraná atualmente é gerido pelo Departamento Penitenciário do Estado em conjunto com a Secretaria de Estado da Justiça e da Cidadania.

As unidades prisionais tem a função de cumprimento de pena em acordo às designações jurídicas, com o objetivo de reinserção social, devendo oferecer condições que possibilitem a realização do que determina a Constituição Federal e a Lei de Execução Penal, a fim de tornar o apenado em egresso reinserido socialmente, integrando-o ao ensino e trabalho justo e igualitário.

\footnotetext{
${ }^{4}$ É o trabalho de pesquisa que faz uso de fontes orais, coletadas por meio de entrevistas/depoimentos gravadas, em diferentes modalidades. Ela passa a ser utilizada a partir dos anos 50 com a invenção e difusão do gravador a fita na Europa, América do Norte e América central e passa a serem utilizadas como método/técnica por historiadores, antropólogos, cientistas sociais, pedagogos, teóricos da literatura. Sabe-se que relatos orais são fontes e servem para a compreensão do passado, ao lado de outros documentos, como diários, fotografias, testamentos e demais documentos escritos. $O$ uso da história oral pode ser compreendido como uma metodologia, uma técnica e uma disciplina. (MEIHY, 2007, p. 5 -17).
} 
Quanto aos processos de ensino nas unidades prisionais, de acordo com o Departamento Penitenciário - DEPEN/PR, "o processo de escolarização no sistema prisional iniciou-se com uma parceria entre a Secretaria de Estado da Justiça e a Secretaria de Estado da Educação, por meio do termo de acordo especial de amparo técnico, em $1^{\text {a }}$ de fevereiro de 1982". Desta feita, a escolarização no âmbito do ensino fundamental e médio se dá por meio da modalidade de ensino supletivo, com os Centros Estaduais de Educação Básica para Jovens e Adultos (CEEBJA).

Garantido na Lei de Diretrizes e Bases - LDB, conforme determina o art. 37:

\begin{abstract}
A educação de jovens e adultos será destinada àqueles que não tiveram acesso ou continuidade de estudos no ensino fundamental e médio na idade própria. $\S 1^{\circ}$ Os sistemas de ensino assegurarão, gratuitamente aos jovens e aos adultos, que não puderam efetuar os estudos na idade regular, oportunidades educacionais apropriadas, consideradas as características do alunado, seus interesses, condições de vida e de trabalho, mediante cursos e exames. $\S 2^{\circ} \mathrm{O}$ Poder Público viabilizará e estimulará o acesso e a permanência do trabalhador na escola, mediante ações integradas e complementares entre si. (BRASIL, 1996).
\end{abstract}

A Lei de Diretrizes e Bases da Educação - LDB (Lei n 9.394/1996), que regulamenta a Constituição Federal de 1988 em seu artigo 208, inciso I, estabelece que toda a população brasileira tem direito ao ensino fundamental - obrigatório e gratuito, sendo assegurada, inclusive, sua oferta para todos os que a ele não tiverem acesso na idade própria. ${ }^{5}$

Desta forma, o sistema penitenciário paranaense conta com a Resolução n 2 de 19 de maio de 2010, a qual dispõe sobre as Diretrizes Nacionais, citada anteriormente, visando à oferta de educação para jovens e adultos privados de liberdade nos estabelecimentos penais. A educação será estabelecida da seguinte forma, de acordo com os artigos $1^{\circ}$ e $2^{\circ}$, da Resolução:

\begin{abstract}
Art. $1^{\circ}$ Ficam estabelecidas as Diretrizes Nacionais para a oferta de educação para jovens e adultos privados de liberdade em estabelecimentos penais, na forma desta Resolução. Art. $2^{\circ}$ As ações de educação em contexto de privação de liberdade devem estar calcadas na legislação educacional vigente no país, na Lei de Execução Penal, nos tratados internacionais firmados pelo Brasil no âmbito das políticas de direitos humanos e privação de liberdade, devendo atender às especificidades dos diferentes níveis e modalidades de educação e ensino e são extensivas aos presos provisórios, condenados, egressos do sistema prisional e àqueles que cumprem medidas de segurança. (BRASIL, 2010).
\end{abstract}

Foram mais de cem anos para se chegar ao sistema prisional paranaense atual. Em relação à assistência educacional, a realidade no Estado do Paraná é relativamente recente, e falta muito a se construir a fim de alcançar as metas prometidas pelo Estado. A Resolução $n^{\circ} 2$ de 2010 foi um impulso na construção educativa dentro das penitenciárias, porém com muitos desafios.

De acordo com o Anuário Brasileiro de Educação Básica (2018, p. 8), se verídico é o fato que a escola não é a solução para todos os problemas, "há evidências científicas suficientes para afirmar que as principais mazelas das quais a sociedade brasileira padece há décadas - ou, por que não dizer, séculos - relacionam-se a um sistema educativo de baixa qualidade", perpetuando diferenças e exclusões.

\footnotetext{
5 Já em âmbito internacional, o documento Regras mínimas para o tratamento de reclusos, aprovado pelo Conselho Econômico e Social da ONU, em 1957, prevê o acesso à educação de pessoas encarceradas.
} 
Para Graciano e Schilling (2008, p. 112) por um lado se tem históricas restrições à educação de jovens e adultos, de outro, há o descaso em relação à educação penitenciária pelas autoridades nacionais responsáveis pela efetivação da educação, "de tal modo que nem as insuficientes ações educativas destinadas à população jovem e adulta chegam ao sistema prisional".

No Estado do Paraná, o Depen tem sob custódia 21.508 presos com índices que aumentam a cada ano. Desses, 10.264 praticam algum tipo de atividade de ensino-aprendizagem. Marca expressiva também em relação a detentos que trabalham. São 6.601 com vínculo empregatício no Paraná ou $30,2 \%$ da população carcerária. (DEPENPR, 2019)

As atividades educacionais no Estado do Paraná se dividem em remição da pena pelo estudo por meio da leitura, Ensino Fundamental, Ensino Médio, Cursos Técnicos, Ensino Superior e Qualificação Profissional, que conta com o maior número de adeptos dentro das penitenciárias. O total de adeptos nas atividades educacionais é de 7.254 sentenciados.

Insta destacar que a Lei de Execução Penal $\left(n^{0} 7.210 / 1984\right)^{6}$ prevê a educação escolar no sistema prisional. Em seu artigo 17, estabelece que a assistência educacional compreende a instrução escolar e a formação profissional do preso. O artigo 18 determina que o ensino fundamental é obrigatório e integrado ao sistema escolar da unidade federativa. E o artigo 21 exige a implementação de uma biblioteca por unidade prisional, para uso de todas as categorias de reclusos, provida de livros instrutivos, recreativos e didáticos.

Com base no INFOPEN (2019, p. 53-54) apenas $12 \%$ da população prisional no Brasil estão envolvidas com alguma atividade educacional, no cômputo estão as de ensino escolar e atividades complementares. Quanto às atividades complementares, $2 \%$ da população prisional do país encontram-se auferindo de atividades de remição pela leitura ou pelo esporte e demais atividades educacionais complementares.

Esses dados são ainda mais preocupantes quando analisados com enfoque nos egressos do sistema prisional. Diante dos problemas enfrentados, a maioria dos apenados cumprem suas penas sem terem participado de quaisquer atividades educacionais, voltando para a sociedade igual ou pior do que antes de ter entrado em uma instituição de ressocialização ou reinserção.

A assistência educacional, conforme o Estatuto Penitenciário do Estado do Paraná, em seu artigo 33, parágrafo único e inciso IV, estabelece que deverá existir no estabelecimento:

Parágrafo Único [...] Instalação destinada a estágio de estudantes universitários. IV. A assistência educacional, a ser prestada por profissionais habilitados, compreende: a) a instrução escolar e a formação profissional do assistido, sob orientação psicopedagógica; b) executar os métodos de tratamento de natureza pedagógica; c) acompanhar diretamente o comportamento do assistido, com a utilização das técnicas psicopedagógica; Material auxiliar de estudo para a prova de múltipla escolha do curso GAAP - "Grupo de Apoio às Ações Penitenciárias" - 2010 d) esclarecer ao assistido sobre as peculiaridades do estabelecimento e atividades ao seu alcance; e) elaborar pareceres pedagógicos reeducativos para completar e colaborar com o estudo da personalidade; f) elaborar pareceres enfatizando as mudanças comportamentais do assistido, para fins de exame criminológico. (ESTATUTO PENITENCIÁRIO DO ESTADO DO PARANÁ, 1995).

\footnotetext{
${ }^{6}$ Disponível em: http://www.planalto.gov.br/ccivil_03/LEIS/L7210.htm
} 
Também, o artigo 35 determina que o ensino do Ensino Fundamental é obrigatório, integrandose no sistema escolar da unidade federativa. O Estatuto no artigo 36 delibera que, "o ensino profissional será ministrado em nível de iniciação ou de aperfeiçoamento técnico. A mulher condenada terá ensino profissional adequado à sua condição". De acordo com o artigo 37 "as atividades educacionais podem ser objeto de convênio com entidades públicas ou particulares que instalem escolas ou ofereçam cursos especializados". Por fim, o artigo 38, levando em consideração as condições locais, cada estabelecimento contará com uma biblioteca, para uso de todas as categorias de assistidos, provida de livros instrutivos, recreativos e didáticos.

Reforça-se que a educação torna-se elemento primaz quando se trata de sistema prisional. A escola dentro de uma unidade de segurança faz com que se efetive possibilidade de capacitação, formação e resgate da cidadania de milhares de cidadãos que foram alijados dessa no decorrer de suas vidas. Mais do que nunca, é necessário concentrar esforços na formação de cidadãos, com atenção especial às pessoas e segmentos sociais historicamente excluídos e subalternizados.

\section{APLICAÇÃO DA PESQUISA, TRATAMENTO DOS DADOS E ANÁLISE DOS RESULTADOS}

Localizado no Sudoeste do Estado do Paraná, o município de Francisco Beltrão (Figura 1), conforme estimativas do IBGE do ano de 2017, conta com uma população de 88.465 habitantes. Fundado em 1952, foi desmembrado do município de Clevelândia. Por meio de desmembramentos ocorridos na década de 1960, foi consolidado com uma área de $731 \mathrm{~km}^{2}$ (PREFEITURA MUNICIPAL DE FRANCISCO BELTRÃO, 2019).

Figura 01: Mapa Político - Localização do Município de Francisco Beltrão/PR

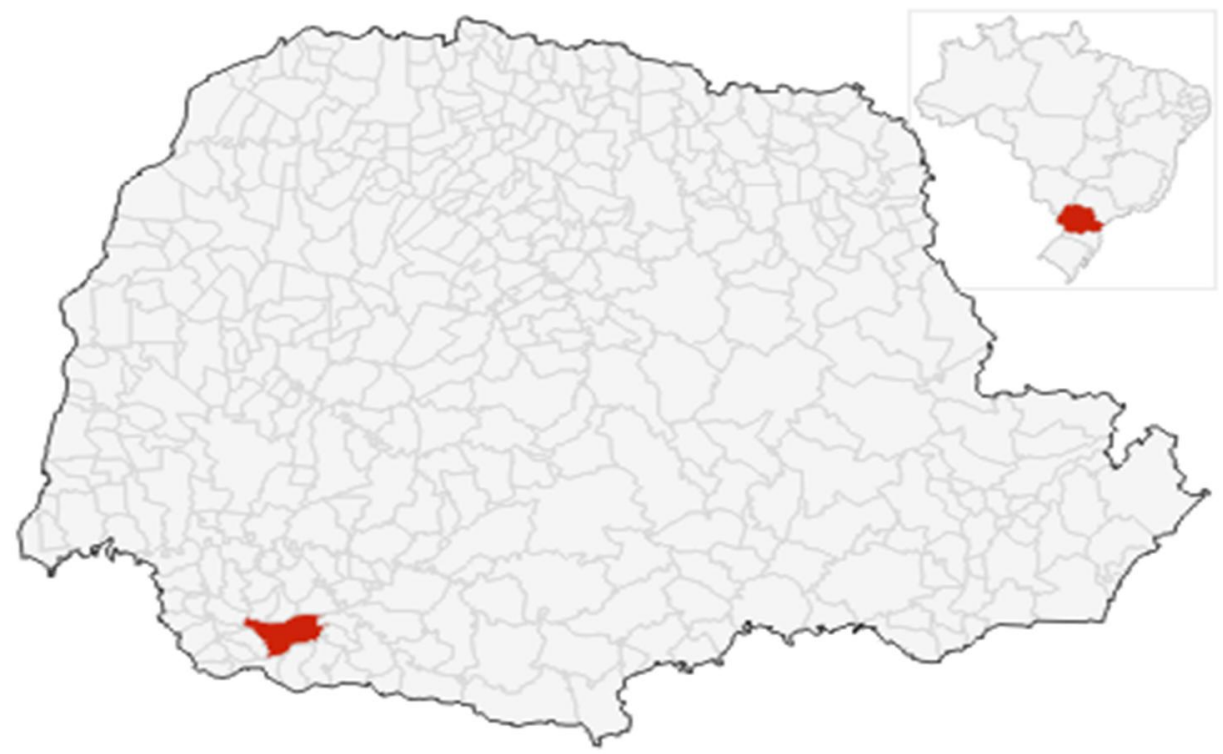

Fonte: Google, 2019.

Em relação à unidade prisional, constata-se que foi inaugurada no dia 07 de maio de 2008. Inicialmente se chamava Centro de Detenção e Ressocialização de Francisco Beltrão - CDRFB, mas em 24 de novembro de 2010 a unidade sofreu alteração de nomenclatura, passando a chamar 
Penitenciária Estadual de Francisco Beltrão - PEFB, nos moldes do Decreto $n^{\circ}$ 8.839/2010, publicado no Diário Oficial $n^{\circ} 8.349$ de 24/11/20107. Sua estrutura física alcança o total de 864 vagas, com área construída de $10.183 \mathrm{~m}^{2}$. É Estabelecimento Penal de Regime Fechado de custódia masculina, localizada na BR 483 no KM 12 (DEPEN, 2019).

Com a construção e funcionamento da penitenciária no município, foi necessário pensar em políticas já praticadas em outras unidades prisionais e estabelecidas em lei que pudessem contribuir para a vida social dos apenados ali inseridos. Dentre as políticas e ações afirmativas, está a assistência educacional, direito garantido pela Lei de Execução Penal.

Implantada em 2008 logo após a inauguração do estabelecimento prisional, a escola na PEFB era vinculada à escola de Educação para Jovens de Adultos do município. A partir de 2012 a escola se desvinculou do município, transformando-se em Centro Estadual de Educação Básica para Jovens e Adultos (CEEBJA), não mais subordinada àquele.

A escola ocupa cinco galerias, as quais são compostas por seis salas cada, distribuídas em diferentes blocos, para atender em média 180 apenados condenados ao cumprimento da pena em regime fechado. Desde o ano de 2011, quando foi implantado o sistema interno de movimentação da escola, até março de 2019, passaram pela unidade prisional e participaram da assistência educacional, aproximadamente 1.349 apenados. ${ }^{8}$

O estudo de caso realizado na unidade prisional de Francisco Beltrão avaliou alguns aspectos do perfil daqueles que auferem da assistência educacional e assuntos referentes ao próprio processo educacional ao qual participam. A pesquisa realizou-se com aplicação de 175 questionários aos apenados que participavam da assistência educacional. Alguns alunos não quiseram participar da pesquisa, por diversos motivos, mas o principal por não saberem ler e escrever. Os dados apresentados adiante fazem parte dessa amostra de questionários respondidos.

Do total de sentenciados que responderam a pergunta referente à idade, a maioria $22,02 \%$ se encontra entre 30 e 39 anos, seguido de apenados entre 40 a 49 anos $(21,1 \%)$ e $16,51 \%$ de jovens entre 25 a 29 anos.

Se comparado aos dados nacionais, com base do INFOPEN (2018) o número de presos com maior percentual varia entre 18 a 24 anos, com taxa de 30\%, uma massa de jovens, enquanto apenas $19 \%$ estão estre 35 a 45 anos. No Estado do Paraná são $29 \%$ dos presos que também se encontram na faixa etária de jovens, se contrapondo a parcela de presos estudantes na PEFB que estão entre 30 a 39 anos. Contudo, é inegável que os dados levam a conclusão que a taxa de aprisionamento de jovens é preocupante.

No tocante a cor, os detentos que se autodenominaram como pardos foram os que mais buscaram acesso a educação enquanto privados de liberdade. A cor predominante de apenados é parda $(50,46 \%)$, seguidos de $27,52 \%$ de brancos e $11,93 \%$ negra.

\footnotetext{
${ }^{7}$ O referido decreto não está disponível para consulta pública.

${ }^{8}$ Considera-se que a unidade prisional possui escola devidamente estruturada e que deve ser aproveitada em benefício dos apenados, observando as normas salutares de segurança. Deste modo, a implantação dos apenados na escola depende do parecer do Setor de Segurança e de Inteligência da Penitenciária.
} 
A maior parte da população prisional nacional com base nos dados do INFOPEN (2018, p. 32) é negra, com $64 \%$, enquanto que a população prisional branca é de $35 \%$, e a população nacional brasileira é formada por $53 \%$ de negros e $46 \%$ de brancos, apontando disparidade entre o número de brancos e negros apenados, uma vez que, o contingente de pessoas brancas apenadas no país é minoria. O que se destaca é a proporção de pessoas negras presas: dois em cada três presos são negros.

As estatísticas brasileiras referentes ao acesso à educação por negros e pardos tornaram-se mais positivas nas últimas décadas, se destacando aquelas relativas à inclusão de diversos grupos sociais. Embora a inclusão esteja entre alguns parcos debates, não é a ideal, pois, não tem sido suficiente para diminuir a flagrante desigualdade social brasileira, influenciando significativamente na quantidade.

Em relação ao perfil socioeconômico dos apenados, a renda mensal familiar foi um fator que influenciou na procura pela educação dentro da detenção, pois, a maioria dos apenados que participam da assistência educacional possui renda familiar mensal de no máximo dois salários mínimos (38,53\% afirmaram ganhar um salário mínimo, seguido de $16,5 \%$ de um a dois salários).

A ausência dos processos educacionais na vida dos apenados, conjuntamente com a renda baixa se comparada à demanda do mercado econômico, ocasionaram o resultado da pesquisa: de acordo com a análise dos dados, os apenados, mesmo antes de serem condenados criminalmente, necessitaram antes de estudar, trabalhar. Foram $53,21 \%$ de apenados que afirmaram ter que trabalhar e não conseguiam conciliar o trabalho com o estudo.

Assunto contundente na sociedade e que interfere em algumas fases do sistema educacional, diz respeito ao consumo de drogas. Na parcela de apenados participantes da pesquisa, não foi um fator que prejudicou demasiadamente a instrução escolar, demonstrando que 5,5\% dos apenados abandonaram os processos educacionais em razão da utilização de drogas.

Fator importante para análise da instrução escolar no sistema prisional refere-se ao tempo de condenação que o apenado deverá cumprir. Na Penitenciária Estadual de Francisco Beltrão, 29,36\% foram condenados ao regime fechado de 10 a 15 anos, seguido de $21,1 \%$ com condenação de 20 a 30 anos e $12,84 \%$ com pena de 15 a 20 anos. Interessante analisar que em relação ao tempo de pena de condenação em razão do crime cometido, o resultado obtido com a pesquisa sugere que quanto mais tempo o detento foi condenado, maior será a sua preocupação em buscar a educação.

Quanto a pena média daqueles que buscaram a assistência educacional ou que se enquadraram nos requisitos administrativos internos da instituição constatou-se que uma grande número passarão mais tempo presos do que estudando quando em liberdade, anterior a prisão.

Observou-se também por meio dos dados obtidos em âmbito nacional, que os mesmos perfis e desigualdades estão se perpetuando na sociedade, como por exemplo, a escolaridade populacional dos presos e a situação de subalternização e vulnerabilização social. No Brasil $51 \%$ dos presos tem o Ensino Fundamental incompleto, e na Penitenciária Estadual de Francisco Beltrão, dos apenados estudantes, $52,29 \%$ estão na mesma modalidade.

O nível de escolaridade influenciou na procura pela continuação do processo de ensinoaprendizagem enquanto encarcerado. A maioria dos sentenciados possuía no máximo o Ensino 
Fundamental incompleto. Parcela dos condenados vem de uma faixa da sociedade que sofre problemas quanto ao acesso e permanência na escola e tem um histórico de trabalho na infância ou adolescência, bem como maus tratos e vítima de violência doméstica.

Foi possível constatar também que grande parte dos depoentes frequentou a escola em curto espaço de tempo - estudaram no máximo 2 anos. A relação entre educação e prisão é um entre tantos outros que compõe os processos de desassistência do Estado, sendo necessário criar medidas para evitar a evasão escolar dos apenados dentro do programa de assistência educacional no sistema prisional, e, essas medidas devem ser coerentes com a realidade do sistema carcerário da unidade. Tem-se a impressão que a desasssitência do Estado ao direito à educação acaba revitimando os encarcerados, pois uma grande parte assume essa negação como uma responsabilidade individual.

Atualmente são 290 apenados (dados do ano de 2019) participando da assistência educacional. Destes, 248 frequentam o Ensino Fundamental e 42 realizam atividades de remissão pelo estudo através da leitura. Comparado ao ano de 2017 houve aumento de vagas, possibilitando atender mais indivíduos, os quais são atendidos por oito professores de sala de aula; 2 Pedagogas da Escola; uma Pedagoga da Unidade; um funcionário da Direção e um Administrativo. Em relação ao investimento referente à educação na unidade prisional, a escola recebe recursos de PDDE e Fundo Rotativo, com o qual fez melhorias nas salas de aulas e dependências administrativas, sendo que, as modalidade de ensino auferidos pelos apenados são EJA presencial e presencial combinados com EaD.

Importante destacar, que o processo de Por meio da pesquisa realizada na unidade prisional fez com que ocorresse uma correlação entre o real e ideal. A realidade diz respeito que, embora esteja em um processo de estruturação, a práxis educacional no sistema prisional começa a alcançar alguns resultados, mesmo em tantos movimentos de nagação do estado para com o sujeitos encarcerados.

\section{VOZES DO CÁRCERE E A METODOLOGIA DE HISTÓRIA ORAL TEMÁTICA}

O uso de metodologia de história oral corresponde a um instrumento importante que possibilita melhorar a compreensão da construção de estratégias de ação e das representações de grupos ou indivíduos da sociedade estudada. Ou seja, dar vez e voz aos protagonistas na teia social. Desta forma, atualmente egresso do sistema prisional, o acadêmico do Curso Superior de Licenciatura em Pedagogia, concedeu entrevista em 28 de novembro de 2018, às 9h30min na Universidade Estadual do Oeste do Paraná. A entrevista foi pautada em questões previamente discutidas e abordadas anteriormente no texto, as quais permearam mais especificamente sobre os processos educacionais e sociais ao qual o entrevistado foi inserido.

Levando em consideração os dados apresentados anteriormente, quanto ao perfil dos apenados da unidade prisional de Francisco Beltrão, o egresso/acadêmico tem renda mensal familiar de três a cinco salários mínimos, solteiro, cor parda e não possui filhos, com faixa etária, na época da pesquisa entre 25 a 29 anos, se enquadrando nos perfis da população prisional nacional.

Dentre as perguntas realizadas, "caso frequente a educação profissionalizante, cursos técnicos ou de ensino superior, informe qual o curso que realiza". A resposta permeou em dado interessante: 
"curso de pedagogia na Unioeste. Quem escolheu o curso foi à equipe prisional da penitenciária e da VEP9".

Verifica-se que ao mesmo tempo em que há o exercício de direito, com a possibilidade de efetivação da educação com o ingresso no ensino superior, retira-se o direito de escolha. Ou seja, o apenado se vê impossibilitado seguir com seus estudos em uma área que deseja que o possibilite ter aproximação com sua autonomia da vontade. O poder de escolha do que aprender de acordo com suas aptidões e interesses deve ser direito dos apenados. Este caminho aponta para a ressignificação e maior atratividade e efetividade desta etapa educacional. A partir do momento que fazem parte da assistência educacional, os apenados tornam-se também, estudantes, e que precisa ser assegurado o direito de escolha sobre o que estudar e o sistema educacional deve usar isso em prol do processo de ensino-aprendizagem, bem como da qualidade da oferta educativa.

Em conversa com os responsáveis pela autorização do ingresso a modalidade de ensino superior, foi informando que a escolha não se deu por parte do apenado, com o objetivo de oportunizar um curso que mais humaniza os indivíduos, com estudo social e educacional.

O depoente egresso também foi questionado se participou de outros cursos ofertados na unidade prisional. Segundo o entrevistado o mesmo participou de curso um curso de língua estrangeira - espanhol enquanto ainda estava na penitenciária, mas não o completou em face de cortes de verba do ente contratante - Governo Federal.

Infelizmente os cortes de verbas no sistema prisional são constantes. A partir das visitas realizadas na PEFB foi possível observar que são ofertados alguns cursos e atividades educacionais, contudo, em sua maioria de curta duração. Embora ocorra o repasse de verbas pelo Fundo Penitenciário, não se sabe exatamente qual é o seu destino final. Importante dizer que nos últimos anos, com base na determinação do Supremo Tribunal Federal, foi repassado ao Fundo Penitenciário Nacional, 1,2 bilhão de reais (2016). Esse valor foi distribuído entre os Estados, sendo que cada Estado recebeu 44,7 milhões para três destinações: ampliação/construção; custeio e aparelhamento. Porém, até o final de 2017, somente 10 Estados utilizaram parte dessa verba.

Nesse sentido, aponta-se para o fato de uma problemática no sistema prisional: a falta de planejamento estratégico. O Estado investe com precariedade na construção de estabelecimentos prisionais de segurança média e máxima e quando o faz assenta-se na morosidade dos processos.

Além dos regimes de pena fechado e aberto, tem o semiaberto. A possibilidade de investimento nesse segmento é mais barato e eficaz diante da realidade brasileira, entretanto depende da alteração da legislação e disponibilidade dos gestores. Outra medida estatal quanto à segurança e cumprimento da pena a ser avaliada, é o investimento em tornozeleiras eletrônicas.

$\mathrm{Na}$ entrevista, a principal pergunta do questionário, refere-se ao que faz com que os apenados busquem a assistência educacional: "principal motivo que o fez retornar aos estudos". Foi entendido pelo egresso que os motivos permeiam em relação "a remição da pena concedida pela justiça"; "ocupação do tempo que preciso cumprir a pena", "busca por conhecimento" e para "buscar uma profissão melhor quando estivesse em liberdade", ou seja, "todos os motivos apresentados foram

\footnotetext{
${ }^{9}$ Vara de Execução Penal.
} 
fatores que contribuíram para a retomada do estudo instrutório. "Entrei pela prova do ENEM através do SISU, nem tinha concluído o ensino médio, eu estudava no cubículo ${ }^{10}$, autodidata. As professoras me deram livros do ensino médio e a remição pela leitura me ajudou muito, eu lia muita literatura clássica".

Observa-se nessa fala que há além do interesse do apenado em permanecer estudando, a necessidade de consolidação de um sistema que não venha carregado de burocracias e negações aos estudantes apenados. Não raro constata-se maior preocupação no atendimento de 'normas e preenchimento de planilhas' que o processo de ensino e aprendizagem em si. Segundo o depoente:

[...] tudo é dificuldade. Sair para prestar prova de seleção = ENEN. Garantir o horário de entrada e saída. Ter transporte. Poder frequentar atividades fora do turno de aulas como as visitas técnicas e as viagens de estudos. Ter algum dinheiro para pagar as cópias que os professores solicitam e até comer alguma coisa [...]

Outra pergunta realizada no decorrer da pesquisa foi o motivo pelo qual não frequentou a escola em idade certa. De acordo com o depoente:

[...] tinha que trabalhar e não sobrava tempo para os estudos"; além, "eu trabalhava com construção civil, comecei a trabalhar muito cedo, como 'boia fria'. A primeira vez que abandonei o estudo foi quando fui para o Rio de Janeiro porque tinha mais oferta, eu trabalhava com meu pai e tio. Não queria ter passado por isso para voltar a estudar, mas agora passou.

Também foi questionado sobre qual a maior motivação para estudar:

[...] minha mãe! A mãe da gente é a grande inspiração e chegar um dia lá na frente e ter condições de contribuir alguma coisa para a humanidade, uma força motivacional. Meu pensamento é fazer Mestrado em Educação e desenvolver uma tese e entrar no Doutorado de Filosofia. Talvez fazer faculdade de Engenharia Civil, o custo é bem alto e era bom que tivesse aqui".

Por meio dessas respostas, se percebe que o apenado pelo fato de ter atuado na área da construção civil rememora uma identidade e a projeta em possibilidade de formação em nível superior. Constata-se dessa forma, que, se fosse oportunizado não somente o acesso ao ensino superior, mas a escolha pelo curso, o egresso poderia estar em outra área.

É possível vislumbrar a importância da educação para o egresso/acadêmico, por meio de suas respostas espontâneas e propositivas. Por isso, é preciso articular a discussão do tema sob o ponto de vista da proteção normativa de direitos violados no âmbito do sistema prisional, que se refere à responsabilidade do Estado, por este tipo de violação, aqui entendida como violação ao acesso a assistência educacional.

A partir da análise da entrevista, se pode perceber que o egresso tem buscado a educação para ter melhores oportunidades tanto do mercado de trabalho como na formação humana e cidadã. $O$ mesmo afirma que a educação pode contribuir significativamente para a ressocialização dos apenados,

${ }^{10}$ Quando os apenados e funcionários das unidades prisionais se referem aos cubículos, quer dizer salas. São
celas de prisão às quais foram transformadas em salas de aula na Penitenciária Estadual de Francisco Beltrão/PR. 
mas que ainda carece de investimento. O fato de uma pessoa estar em regime de privação de liberdade não the confere a perda do demais Direitos Fundamentais.

Dentre os direitos e garantias fundamentais, a Constituição Federal proíbe as penas cruéis (art. $5^{\circ}, \mathrm{XLVII}, \mathrm{e}, \mathrm{CF} / 88$ ), e garante ao cidadão-preso o respeito à integridade física e moral (art. $5^{\circ}, \mathrm{XLIX}$, CF/88). Parte-se do pressuposto de que os direitos fundamentais são os direitos humanos previstos na Carta Magna, em leis e tratados internacionais, ou que decorrem da aplicação destes, que têm eficácia e aplicabilidade imediata, e estão baseados no princípio da dignidade humana.

\section{CONCLUSÃO}

A pesquisa buscou estudar o direito de acesso à educação pelos apenados no sistema prisional brasileiro, com enfoque no Estado do Paraná, principalmente na Penitenciária Estadual de Francisco Beltrão, unidade prisional masculina de segurança média. Evidenciou-se que a educação é compreendida como Direito Fundamental Social e de extensão a todos - incluindo aqueles que estão sob a custódia do Estado, na situação de restrição à liberdade.

O processo de ensino escolar aos apenados e as dificuldades para alcançar o fim da pena ou prisão, recaem sobre os empecilhos da formação dos professores, a insuficiência de recursos humanos, didáticos, tecnológicos, ausência de programas governamentais que destaquem o papel da educação penitenciária na ressocialização do detento, e a ausência do apoio dos próprios governantes, que restringem geralmente pelo uso da burocracia o acesso educacional aos presos.

A assistência educacional é um direito de todos, direito este, garantido no Brasil, através da Declaração Universal dos Direitos Humanos, Constituição Federal, Lei de Diretrizes e Bases de Educação, Decreto-Lei $n^{0}$ 7.626/2011 e pela Lei de Execução Penal. É responsabilidade do Estado citado no artigo $5^{\circ}$ da Constituição Federal/1988 e no artigo 10 da Lei de Execução Penal, a assistência ao preso e ao internado, objetivando prevenir o crime e orientar o retorno à convivência em sociedade.

Diversas leis foram citadas a fim de efetivar o acesso à educação pelos apenados. Nesse sentido, a lei, como norma jurídica aprovada pelos representantes do povo, exerce o papel fundamental de reger a sociedade e o Estado segundo a democracia. A sua importância é tão notória que o resultado da produção legislativa adquire autonomia em face do ente que a produz. As matérias tratadas pela lei devem ser analisadas, pois o seu objetivo é estabelecer a disciplina geral das questões necessárias à harmonia da coletividade.

Por fim, os dados apresentados evidenciam que a população prisional é sim, composta por maioria de cor parda ou negra, jovem, com baixas condições econômicas e com baixa escolaridade. Realidade essa assentada no processo de segregação histórica a centenas de categorias no Brasil desde a implantação do processo de ocupação e povoamento, reforçados pelos processos do colonialismo e da colonialidade do poder, do saber e do ser.

Unir pesquisa bibliográfica e de campo permitiu concluir que não basta o Estado punir. É preciso antes de qualquer medida penal, oferecer condições dignas de vida para a população e equidade em direitos, principalmente educação, que possibilite a garantia da dignidade humana e cidadania a todas as categorias sociais. 
Segundo Bittencourt (2003 p.11), no momento em que se defende a garantia dos direitos fundamentais, e o respeito à dignidade do cidadão privado de liberdade, é necessário que o Direito Penal seja interpretado à luz da Constituição e compreendido como ultima ratio, no sentido de atuar apenas quando os demais ramos do Direito forem incapazes de tutelar os bens relevantes à vida do indivíduo e da própria sociedade. Do contrário, continuará servindo como instrumento de exclusão social, e em pouco tempo não haverá mais lugar para o homem nas casas prisionais.

\section{REFERÊNCIAS}

1. BRASIL. Lei $n^{\circ}$ 7.210, de 11 de julho de 1984. Institui a Lei de Execução Penal. Brasília, DF, 11, jul., [1984]. Disponível em: http://www.planalto.gov.br/ccivil_03/LEIS/L7210.htm. Acesso em: 20 de dez. de 2018. Federal, [2016]. Disponível em: http://www.planalto.gov.br/ccivil_03/Constituicao/Constituicao.htm. Acesso em: 20 dez. 2018

Lei $n^{\circ}$ 9.394, de 20 de dezembro de 1996. Estabelece as diretrizes e bases da educação nacional. Brasília, DF, 20, dez., [1996]. Disponível em: http://www.planalto.gov.br/ccivil_03/LEIS/L9394.htm. Acesso em: 20 dez. 2018.

Resolução $n^{\circ}$ 2, de 19 de maio de 2010. Dispõe sobre as Diretrizes Nacionais para a oferta de educação para jovens e adultos em situação de privação de liberdade nos estabelecimentos penais. Brasília, DF, 20 maio [2010]. Disponível em: http://portal.mec.gov.br/index.php?option=com_content\&view=article\&id=14906. Acesso em: 17 jan. 2019. . Decreto Estadual no. 1276 de 31 de outubro de 1995. Estatuto Penitenciário do Estado do Paraná. $1995 . \quad$ Disponível em: http://www.depen.pr.gov.br/arquivos/File/Estatuto_Penitenciario_1.pdf. Acesso em: 08 maio 2019. Anuário Brasileiro da Educação Básica: Pesquisa Nacional por Amostra de Domicílios Pnad. Instituto Brasileiro de Geografia e Estatística. Disponível em: https://todospelaeducacao.org.br/_uploads/20180824-

Anuario_Educacao_2018_atualizado_WEB.pdf?utm_source=conteudoSite. Acesso em: 14 maio 2019. 

http://www.ipea.gov.br/portal/index.php?option=com_content\&view=article\&id=33410\&ltemid=432. Acesso em: 14 maio 2019.

8. Penitenciário Nacional, 2016. Disponível em: http://depen.gov.br/DEPEN/noticias1/noticias/infopen-levantamento-nacional-de-informacoes-penitenciarias2016/relatorio_2016_22111.pdf. Acesso em: 17 jan. 2019.

9. Formação e Aperfeiçoamento Penitenciário - ESPEN. 2019. Disponível em: http://www.espen.pr.gov.br/. Acesso em: 08 maio 2019.

FRANCISCO BELTRÃO. Procedimento Administrativo nº 04/2015, autos $n^{\circ}$ 0054.15.000503-8, de 18 de agosto de 2015. Vara de Execução Penal, Tribunal de Justiça do Estado do Paraná. 2015.

Beltrão. Disponível em: http://www.franciscobeltrao.pr.gov.br/departamentos/turismo/economiatecnologia/perfil-do-municipio/. Acesso em: 29 jan. 2019.

BITENCOURT, Cezar Roberto. Tratado de Direito Penal. Parte Geral. 8. ed. São Paulo: Saraiva, 2003. v. 1.

GRACIANO, Mariângela; SCHILLING, Flávia. A educação na prisão: hesitações, limites e possibilidades. Estudos de Sociologia, Araraquara, SP: v.13, n.25, p.111-132, 2008. Disponível em: http://www.cmv-educare.com/wp-content/uploads/2012/07/Graciano-e-Schilling-2008.pdf. Acesso em: 08 maio 2019.

14. MEIHY, José Carlos Sebe Bom. Manual de história oral. São Paulo: Loyola, 2007.

15. MENEGOTO, Camila Taís. O plano estratégico de educação no âmbito do sistema prisional brasileiro: um estudo de caso na Penitenciária Estadual de Francisco Beltrão - PR. 2017. Disponível em: https://sisbib.unioeste.br/pergamum/biblioteca/index.php. Acesso em: 14 dez. 2018.

SILVEIRA, Maria Helena Pupo. O processo de normalização do comportamento social em Curitiba: educação e trabalho na Penitenciária do Ahú, primeira metade do século XX. Tese (Doutorado em Educação) - Universidade Federal do Paraná, Curitiba, PR. 2009. Disponível em: http://www.ppge.ufpr.br/teses/D09_silveira.pdf. Acesso em: 08 maio 2019. 
17. SILVESTRE, Giane; MELO, Felipe Athayde Lins de. Encarceramento em massa e a tragédia prisional brasileira. Instituto Brasileiro de Ciências Criminais. 2017. Disponível em: https://www.ibccrim.org.br/boletim_artigo/5947-Encarceramento-em-massa-e-a-tragedia-prisionalbrasileira. Acesso em: 24 jun. 2019.

18. SINHORETTO, Jacqueline; LIMA, Renato Sérgio de. Narrativa autoritária e pressões democráticas na segurança pública e no controle do crime. Revista Contemporânea - Dossiê Violência, crime e teoria social. v. $5, \quad$ n. 1 p. 119-141, 2015. Disponível em: http://www.contemporanea.ufscar.br/index.php/contemporanea/article/view/299/131. Acesso em: 24 jun. 2019.

\section{Camila Tais Menegoto}

Mestre em Educação na Universidade Estadual do Oeste do Paraná-UNIOESTE; Pós-graduanda em Direito do Trabalho e Direito Processual do Trabalho através no Centro Sulamericano de Ensino Superior; Graduada no curso de Direito da Universidade Estadual do Oeste do Paraná/UNIOESTE; Docente na Educação Infantil e Ensino Fundamental, formada pelo Colégio Estadual de Pato Branco PR. Atuou como monitora Bolsista do Projeto CUIA/UNIOESTE. Atuou como estagiária de graduação na Vara Criminal no Tribunal de Justiça do Estado do Paraná, Comarca de São João - PR. Advogada e Conciliadora do Juizado Especial Cível e Criminal na Comarca de Marmeleiro/PR.

\section{Thaís Janaina Wenczenovicz}

Docente adjunta na Universidade Estadual do Rio Grande do Sul/UERGS. Professora no Programa de Pós-Graduação em Educação/UERGS. Professora Colaboradora no Programa de Pós-graduação Stricto Sensu em Educação da Universidade Estadual do Paraná - UNIOESTE. Professora Titular no Programa de Pós-Graduação Stricto Sensu em Direito/UNOESC. Avaliadora do INEP - BNI ENADE/MEC. Membro do Comitê Internacional Global Alliance on Media and Gender (GAMAG) UNESCO. Líder do Grupo de Pesquisa CNPq/UERGS Direitos Humanos e Justiça: perspectivas decoloniais.

\section{Como citar este documento:}

WENCZENOVICZ, Thaís Janaina; MENEGOTO, Camila Tais. A Educação no Sistema Prisional: experiência educacional na penitenciária estadual de Francisco Beltrão/PR. Reflexão e Ação, Santa Cruz do Sul, v. 28, n. 3, p. 66-80, ago. 2020. ISSN 1982-9949. Disponível em: $<$ https://online.unisc.br/seer/index.php/reflex/article/view/13984>. Acesso em: doi:https://doi.org/10.17058/rea.v28i3.13984. 